\title{
Editorial
}

\section{Cross-disciplinary collaboration: social medicine, community medicine, and health economics}

In July 1978 a meeting was held in Trinity Hall, Cambridge, under the auspices of the University Department of Community Medicine. Its purpose was to bring together research workers in health economics and those working in social and community medicine so that the two groups could examine their different viewpoints in the hope of seeking and establishing common glound. The papers prepared for general discussion, together with some commentaries on them, appear in this issue of Epidemiology and Community Health. Most of the participants were members of the Health Economics Study Group and the Society for Social Medicine, and a grant from the Social Science Research Council helped with the costs of the meeting.

The idea of a collaborative meeting seemed a happy one for several reasons, all of which are connected with the probable benefits of greater research collaboration between the groups. The most obvious reason is the substantial overlap in the problems tackled, as can be seen by a cursory glance at the relatively specialised journals used by the two groups, particularly those journals under an' effectiveness' rubric, and those exploring environmental and behavioural causes of ill-health. This applies also to problems of method and interpretation, such as absence of information on outcomes, ignorance of aetiology, and proper ways of incorporating value judgements. Some of this common ground is increasingly being made evident by the fact that members of each group often publish in the same journals; indeed some intrepid people have even become members of professional societies or study groups in both fields.

There were, however, other straws in the wind. One was the import and export of each other's terminology -not always, perhaps, used as it should be. Another was a growing awareness on both sides that multidisciplinary methodology was often the only way of proceeding usefully in tackling important problems. Yet another was a growing identity problem' on each side. The health economists have been tending to resist the use of the qualifying adjectival noun 'health' but recognising at the same time that health is not just another area for the application of economic theory. Indeed, the special features of the economics of health are beginning to influence the mainstream of economic theory and to enrich its generality-for example, by way of the ideas of human capital, or of goods not necessarily being ends in themselves but a means to higher ends. For their part, those in social medicine seem increasingly concerned about the connotation of 'social' and 'community' in the description of their activities - a concern which some feel to be indicated most vividly in the recent change of title of this journal.

When the economists initially proposed a collaborative meeting, the ground to be tilled therefore seemed fertile enough, and the tillers flexible enough, for there to be every prospect of a fruitful harvest.

The agreed rules were tough. There was to be strict equality of numbers between the groups; Alan Williams and Roy Acheson, who were responsible for writing the opening papers, were required to prepare themselves by reading 200 pages of representative material supplied by the 'other side' and to explore this material each using his own subject's methods and his own critical sense of priority (Williams was surprised to find a large proportion of his references in the sociological literature); an injunction was issued forbidding cheap pointscoring or an assertion of hegemony by anyone; it was presumed that all participants would have read all the papers before sessions. Finally, none of the seven authors of the basic papers was allowed to present his material: he could speak only when spoken to! All these rules were respected. It has not proved feasible to publish the open discussion here but this was every bit as interesting as what follows.

What came of it all? We shall not attempt the rough justice of a synopsis, nor shall we list our various points of agreement and disagreement. Although there was disagreement it would be hard to itemise, because it cut across the interdisciplinary divide and seemed to reflect no basic or systematic philosophical or methodological divergence between the two groups en masse. It might have been useful to have totted up the answers to the questions Alan Williams posed towards the end of his paper, together with the answers to an equivalent set of questions in which 'social medicine' is replaced with 'economics'. However, direct answers were not, alas, forthcoming.

We content ourselves, therefore, by noting two major impressions of the meeting. In the first place, it was clearly demonstrated that one area for fruitful collaborative work - perhaps the area - is the effectiveness/efficiency analysis of specific health care 
procedures. Here, clinical medicine and epidemiology on the one hand, and economics and sociology on the other, are manifestly more productive when taken together than any is alone. At least, that seemed to be the consensus of opinion at the meeting, although there was occasionally a feeling that each of the two groups contained the odd Procrustes or two, for whom either traditional public health or the theory of markets, as the case may be, provided the only proper way forward to solving the health problems of the world. If these did not work, it was the world, rather than the methods, that needed stretching or chopping.

Secondly, although it turned out that the economists were the more 'theoretical' of the two groups, as might have been expected, and that the doyens of social and community medicine were the more 'pragmatic', there was a surprising and encouraging amount of overlap between the distributions of interest thus categorised. Rory Williams's paper in particular brought this home, and it was striking that his principled and systematic exploration was received with greater impatience by the pragmatic wing of his own party than by any economist. Most of the economists, we suspect, were relieved to find economic language used accurately and not unsympathetically by a social medicine man.

A third important point is worth adding. Many of those experienced in multidisciplinary gatherings thought that this one was remarkable because it was thoroughly pervaded with mutual respect and unpatronising tolerance. That alone, we suggest, justified the meeting, especially if respect and tolerance lead to future collaborative studies. 